\title{
Design of Hybrid Fuzzy and Position-Velocity Controller for Precise Positioning of a Servo System
}

\author{
Esam H. Abdelhameed \\ IEEE member \\ Faculty of Energy Engineering, Aswan \\ University \\ Aswan, Egypt \\ ehhameed@yahoo.com
}

\author{
Tarek Hassan Mohamed \\ Marwa Mahmoud Hamed \\ Faculty of Energy Engineering, Aswan \\ University \\ Aswan, Egypt \\ oldmemories.1991@gmail.com
}

\author{
Gaber El-saady Ahmed \\ Faculty of Engineering, Assuit \\ University \\ Assuit, Egypt \\ gaber1@yahoo.com
}

\begin{abstract}
Nowadays, new technologies demand precision servo systems that have ability to provide high accuracy motion and to reject system disturbance such as load disturbance. In our previous paper (2018), the control performance of a servo system (a cart driven by a DC motor) has been improved through scheduling the parameters of a position-velocity controller according to the concept of fuzzy logic scheme. However, the targeted performance requirements such as settling time and peak overshoot still a challenging point. In order to provide high positioning accuracy, a hybrid fuzzy and position-velocity controller has been proposed in this study as a robust control scheme against the load disturbance. The effectiveness of the proposed scheme has been investigated using a numerical simulation. The obtained results are discussed and compared with those of our previous study.
\end{abstract}

Keywords-position-velocity controller, Fuzzy controller, DC servo motor, Motion Control, Load disturbance rejection.

\section{INTRODUCTION}

$\mathrm{S}$ ervo mechanisms especially DC servo motor considered the heart of a different applications in many fields, Those play a spirited role in the improvement and development of the industrial revolution [1], [2] [3]. Despite the high reliability, flexibility and low cost of the DC motor, there are major problems that disserve servo motor control like the time-varying nature of motor parameters, nonlinear characteristics and rejection disturbances [4], [5]. So, designing of robust and precision controllers for such systems is one of the most challenging researches [6].

In general, it is difficult to achieve the desired control performance when applying cascaded position-velocity controller to nonlinear and uncertainty systems due to the dynamic nature of these systems. Therefore, modern and intelligent control techniques can be designed to limit the drawbacks of those systems. One of these techniques is the fuzzy logic controller [7] that has been studied in this paper. Fuzzy logic theory played a vital role in designing smart controllers that can eliminate or manipulate undesirable effects found in servo systems and improve their performance [8].

Recently, there were many researches which concerned with Fuzzy logic scheme techniques [9], [10]. Our previous paper (2018) presented one of those techniques, that depend on updating the gains of a position-velocity controller according to fuzzy inference system (FIS) and called fuzzy supervised position-velocity (FSPV) controller [11]. Consequently, this paper play as a complement to the previous one where it proposes a new intelligent technique based on hybridizing between fuzzy logic controller and the traditional position-velocity controller for improving the performance of the servo system.

In the following sections: Circuit and block diagrams of the DC servo system have been explained in section II, Then, the control system configurations have been discussed in detail in section III. But about section IV, results of the numerical simulation and discussion have been provided. Finally, the conclusion has been presented in section V.

\section{SYSTEM STRUCTURE}

Figure 1 illustrates the structure of the system used in this study. As it is clear, it's a solid aluminum cart which is moved by a DC motor, that is equipped with a planetary gearbox with a reduction ratio of 3.71:1. To ensure a consistent and continuous tracking, and avoid slippage, a linear bearings used for helping the cart to slide over a stainless steel shaft as well as a rack-pinion mechanism which guided it. The linear position of the cart is measured using an optical incremental encoder via the rack-pinion combination. The position signal is measured and fed back to implement a closed control system [2].

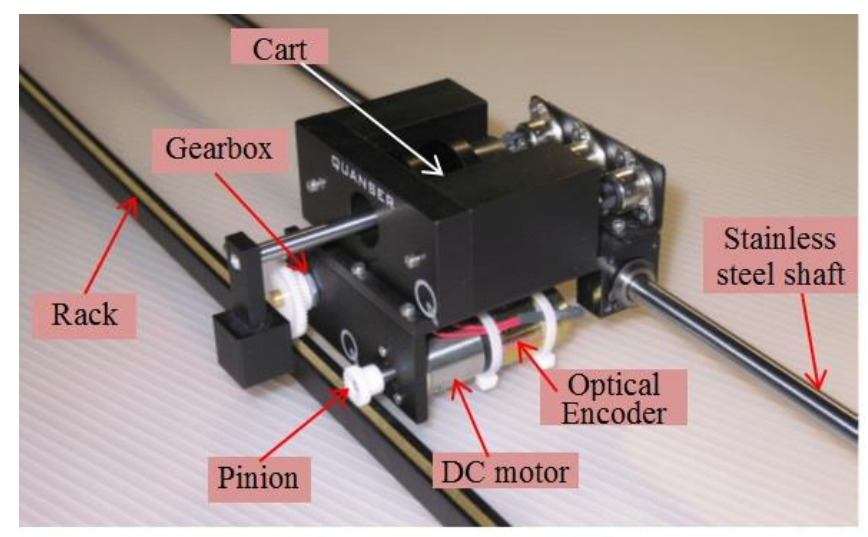

Fig. 1. Servo System Structure

In order to model the system, the transfer function of the cart driven by DC motor has been driven based on basic mechanical and electrical principles, where the commanded 
voltage to DC motor is considered the input of the servo system and the output is the cart linear position which is measured using a digital single ended quadrature optical shaft encoder that provides a high resolution of 4096 counts per one turn [12].

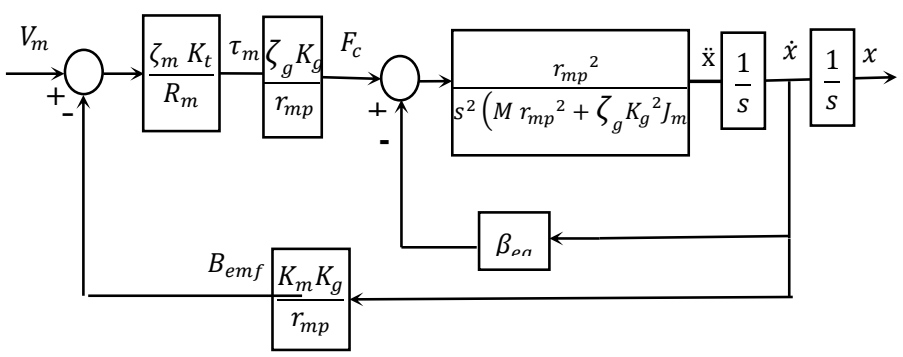

Fig. 2. Schematic Servo System diagram

where, $\tau_{m}$ is the generated torque by the motor, $F_{c}$ is the force that the DC motor applies on the cart, $\theta_{m}$ is the angular position of the motor shaft, $\omega_{m}$ is the angular velocity of the cart, and $B_{e m f}$ is the back electromotive force. The variables $x$, and $\dot{x}$ are the cart linear displacement, linear velocity, respectively. The transfer function of the DC servo system can be formulated by $G(s)$ which is described in (1).

$$
G(s)=\frac{\theta_{m}(s)}{V_{m}(s)}=\left(A_{m} / J_{e q}\right) /\left(s+B_{e q} / J_{e q}\right)
$$

The parameters of equation (1) can be defined as follows:

$$
\begin{gathered}
A_{m}=\frac{\zeta_{g} \zeta_{m} K_{t} K_{g}}{r_{m p} R_{m}} \\
J_{e q}=M+\frac{J_{m} \zeta_{g} K_{g}^{2}}{r_{m p}^{2}} \\
B_{e q}=\frac{\zeta_{g} \zeta_{m} K_{t} K_{m} K_{g}^{2}}{r_{m p}^{2} R_{m}}
\end{gathered}
$$

Where the parameters of the servo system are listed in the following table [12].

TABLE I. SERVo SyStem PARAMETERS \& SPECIFICATIONS

\begin{tabular}{|c|l|c|l|}
\hline \multicolumn{4}{|c|}{ Servo System Parameters } \\
\hline$M$ & Mass of the cart and cart load & 0.94 & $\mathrm{~kg}$ \\
\hline$J_{m}$ & Rotor moment of inertia & $3.9^{*} 10^{-7}$ & $\mathrm{Kg} \cdot \mathrm{m}^{2}$ \\
\hline$\zeta_{\mathrm{g}}$ & Planetary gearbox efficiency & 100 & $\%$ \\
\hline$\zeta_{m}$ & Motor efficiency & 100 & $\%$ \\
\hline$K_{t}$ & Motor torque constant & 0.00767 & $\mathrm{~N} . \mathrm{m} / \mathrm{A}$ \\
\hline$K_{g}$ & Planetary gearbox gear ratio & 3.71 & \\
\hline$r_{m p}$ & Motor pinion radius & $6.35^{*} 10^{-3}$ & $\mathrm{~m}$ \\
\hline$I_{\max }$ & Maximum input current & 4.0 & $\mathrm{~A}$ \\
\hline$K_{m}$ & Motor back EMF constant & 0.00767 & $\mathrm{~V} \cdot \mathrm{sec} / \mathrm{rad}$ \\
\hline$R_{m}$ & Motor armature resistance & 2.6 & $\Omega$ \\
\hline
\end{tabular}

\section{HYBRID FUZZY/PV CONTROLLER}

For designing Mamdani-type fuzzy inference system, and in order to have ability to generate suitable variables that lead the system to the perfect target, there are four vital and important keys must be defined [13][14]. Figure 3 shows the four keys which can be described as follows:

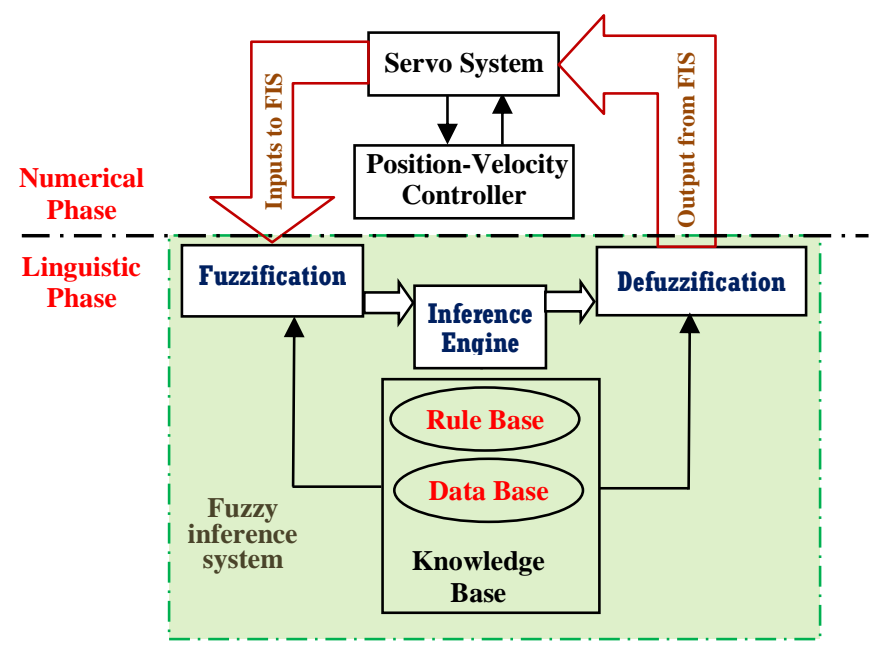

Fig. 3.Fuzzy Inference System Structure

\section{- Fuzzification:}

This process is responsible on preparing the input data from numerical case into linguistic. In this study, there are two inputs which respect the position error signal and the velocity error signal of the system.

\section{- Knowledge Base:}

This stage consists of rule base and data base that can be used to determine the number of fuzzy rules and membership function of fuzzy sets. Seven triangle membership functions have been used in this article for each system input as shown in Fig. 4 and Fig. 5.

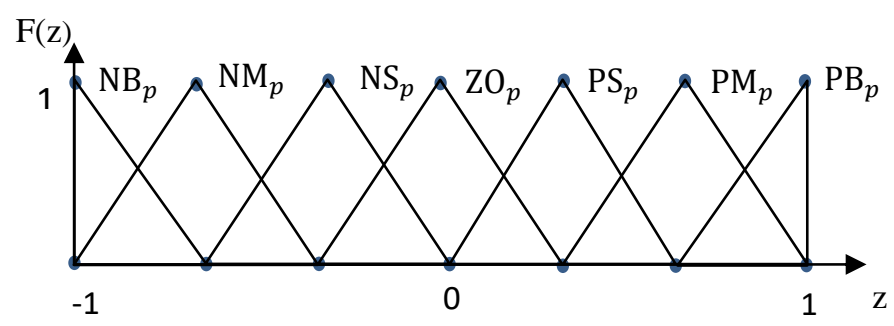

Fig. 4. The input membership function respected with position error signal

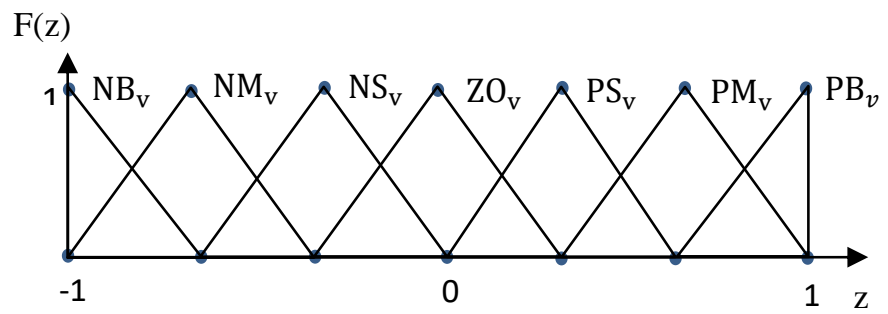

Fig. 5. The input membership function respected with velocity error signal

where NB, NM, NS, ZO, PS, PM, PB refer to Negative Big, Negative Medium, Negative Small, Zero, Positive Small, Positive Medium and Positive Big, respectively. But about the subscript letter $p \& v$ indicated to position and velocity error signals, respectively. 


\section{- Inference Engine:}

The inference engine determines which control rule to be used. Furthermore, the inference engine is the most important component in FIS because it defines the relationship between input and output across pre-determined IF-THEN rules, which are simulated to make human decisions based on vague concepts using Mamdani-type fuzzy system.

\section{- Defuzzification:}

Defuzzification is the last process in the FIS which is responsible of converting the resultant variables from inference engine process into numerical variables. There are several methods of the defuzzification process. This paper uses the Center of Gravity (CoG) defuzzification method that is the most widely used and very accurate method. Accordingly, the CoG can be calculated as:

$$
Z^{*}=\left(\int_{z_{\min }}^{z_{\max }} \mathrm{f}(\mathrm{z}) \cdot \mathrm{zdz}\right) /\left(\int_{\mathrm{z}_{\min }}^{\mathrm{z}_{\max }} \mathrm{f}(\mathrm{z}) \cdot \mathrm{dz}\right)
$$

Where $z$ is the value of the linguistic variable, and $\left[\begin{array}{ll}z_{\min } & z_{\max }\end{array}\right]$ represents the range of the linguistic variable.

Figure 6, presents the schematic diagram of the proposed control system. It's obvious clear that the proposed technique depends on hybridizing two types of controllers for obtaining precision control. Through this control technique the advantages of both fuzzy logic and position-velocity controller can be gained to provide a desired response of the servo system. The fuzzy inference system aids PV controller to generate more suitable control signal by summing their efforts. The main concern in this study is to minimize the effect of load disturbances that affect both the cart speed and position. And improve the transient response i.e. settling time and peak over shooting of the positioning performance. Moreover, as the DC servomotor may suffer from saturation effect, in which the output of the motor cannot reach the desired value, improving the DC Servo motor performance under the presence of load disturbance and avoiding saturation case is taken into consideration during fuzzy controller design.

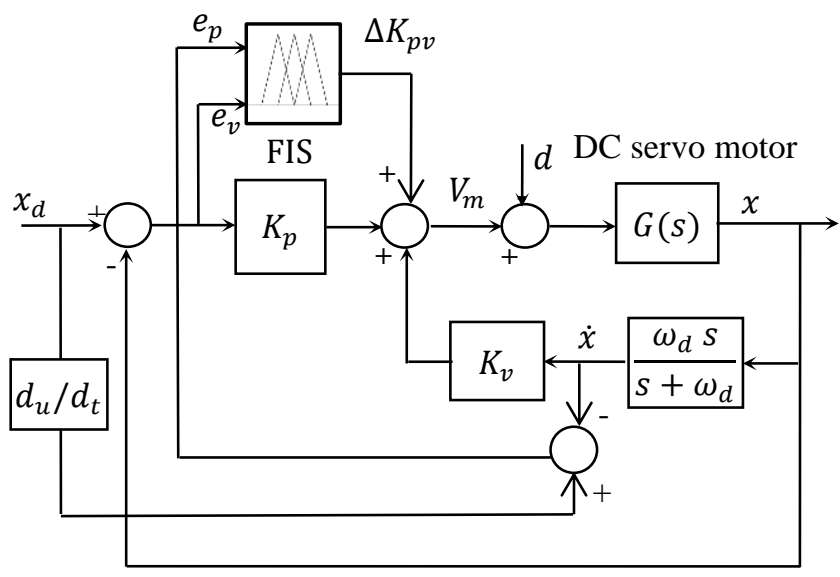

Fig. 6. Schematic diagram of the proposed controller (Hybrid FIS/PV).
As shown in Fig. 6 the positioning error signal $e_{p}$ which is the difference between the positioning reference $x_{d}$ and the measured linear displacement $x$, and velocity error signal $e_{v}$ which is the difference between the velocity reference (the derivative of the positioning reference $x_{d}$ ) and cart velocity (the derivative of the cart position $x$ ) are utilized as the inputs of the fuzzy controller. The matrix rules used in this study is illustrated in table II.

TABLE II. MATRIX OF FUZZZY RULES

\begin{tabular}{|l|l|l|l|l|l|l|l|}
\hline & $N \boldsymbol{B}_{v}$ & $N \boldsymbol{M}_{v}$ & $N \boldsymbol{S}_{v}$ & $Z \boldsymbol{O}_{v}$ & $\boldsymbol{P S}_{v}$ & $\boldsymbol{P M}_{v}$ & $\boldsymbol{P} \boldsymbol{B}_{v}$ \\
\hline$N \boldsymbol{B}_{p}$ & $N B_{\boldsymbol{u}}$ & $N B_{\boldsymbol{u}}$ & $N B_{\boldsymbol{u}}$ & $N B_{\boldsymbol{u}}$ & $N M_{\boldsymbol{u}}$ & $N S_{\boldsymbol{u}}$ & $Z O_{\boldsymbol{u}}$ \\
\hline$N M_{p}$ & $N B_{\boldsymbol{u}}$ & $N B_{\boldsymbol{u}}$ & $N B_{\boldsymbol{u}}$ & $N M_{\boldsymbol{u}}$ & $N S_{\boldsymbol{u}}$ & $Z O_{\boldsymbol{u}}$ & $P S_{\boldsymbol{u}}$ \\
\hline$N S_{p}$ & $N B_{\boldsymbol{u}}$ & $N B_{\boldsymbol{u}}$ & $N M_{\boldsymbol{u}}$ & $N S_{\boldsymbol{u}}$ & $Z O_{\boldsymbol{u}}$ & $P S_{\boldsymbol{u}}$ & $P M_{\boldsymbol{u}}$ \\
\hline$Z \boldsymbol{O}_{p}$ & $N B_{\boldsymbol{u}}$ & $N M_{\boldsymbol{u}}$ & $N S_{\boldsymbol{u}}$ & $Z O_{\boldsymbol{u}}$ & $P S_{\boldsymbol{u}}$ & $P M_{\boldsymbol{u}}$ & $P B_{\boldsymbol{u}}$ \\
\hline $\boldsymbol{P S}_{p}$ & $N M_{\boldsymbol{u}}$ & $N S_{\boldsymbol{u}}$ & $Z O_{\boldsymbol{u}}$ & $P S_{\boldsymbol{u}}$ & $P M_{\boldsymbol{u}}$ & $P B_{\boldsymbol{u}}$ & $P B_{\boldsymbol{u}}$ \\
\hline $\boldsymbol{P M}_{p}$ & $N S_{\boldsymbol{u}}$ & $Z O_{\boldsymbol{u}}$ & $P S_{\boldsymbol{u}}$ & $P M_{\boldsymbol{u}}$ & $P B_{\boldsymbol{u}}$ & $P B_{\boldsymbol{u}}$ & $P B_{\boldsymbol{u}}$ \\
\hline $\boldsymbol{P B}_{p}$ & $Z O_{\boldsymbol{u}}$ & $P S_{\boldsymbol{u}}$ & $P M_{\boldsymbol{u}}$ & $P B_{\boldsymbol{u}}$ & $P B_{\boldsymbol{u}}$ & $P B_{\boldsymbol{u}}$ & $P B_{\boldsymbol{u}}$ \\
\hline
\end{tabular}

\section{RESULTS AND DISCUSSION}

Numerical simulation using MATLAB/Simulink software has been carried out to validate the influence of the proposed controller under taken the load disturbance $d$ and using S-shape command as a reference trajectory which are shown in Fig. 7. Figures 8-11 show the results of the proposed controller (Hybrid Fuzzy/PV) and illustrate a comparison with those obtained when using the Fuzzy supervised PV controller (FSPV) and classic PV Controller which are designed in [11]. Performance of the DC Servo mechanism under load disturbance is shown in Fig. 8, that of the proposed hybrid controller is shown as solid blue line, that of Fuzzy Supervised PV Controller is shown as dash green line, and that of PV conventional controller is shown as dot red line. It is clear from the figure that, there is obvious improvement in the positioning performance with the proposed hybrid controller comparing with the other two controllers, this improvement is illustrated in values of settling time and peak overshoot of the positioning mechanism performance with of the three controllers in Table III

\section{TABLE III. DC SERVO MOTOR RESPONSE CHARACTERISTICS}

\begin{tabular}{|c|c|c|}
\hline \multicolumn{3}{|c|}{ DC Servo Motor response characteristics } \\
\hline Type of Controller & P.O & Ts \\
\hline PV Controller & $0.4115 \mathrm{~mm}$ & $0.246 \mathrm{sec}$ \\
\hline FSPV Controller & $0.3517 \mathrm{~mm}$ & $0.181 \mathrm{sec}$ \\
\hline Hybrid FIS/PV & $0.154 \mathrm{~mm}$ & $0.057 \mathrm{sec}$ \\
\hline
\end{tabular}



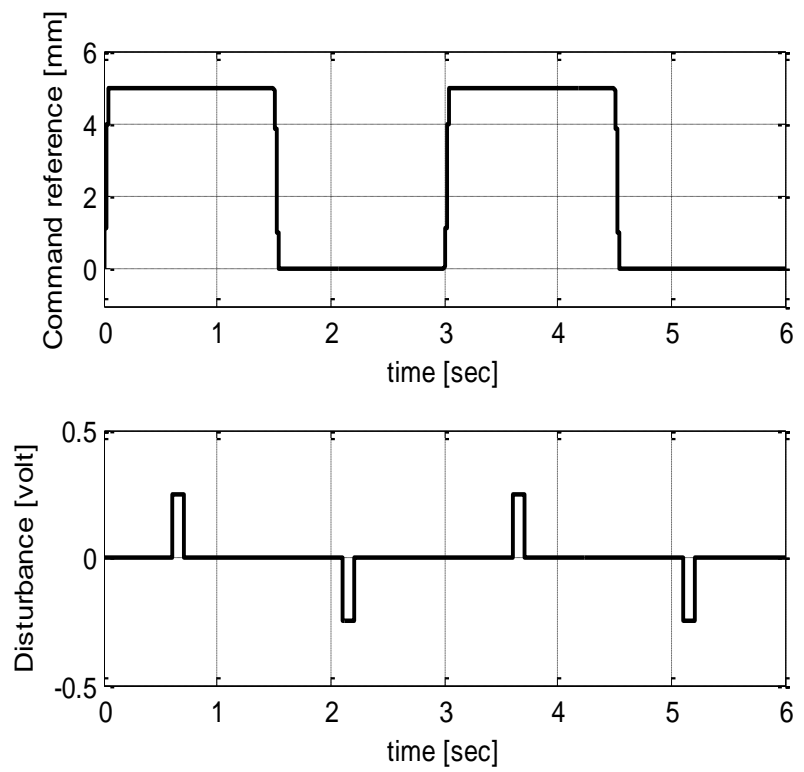

Fig. 7.Reference and Disturbance Command

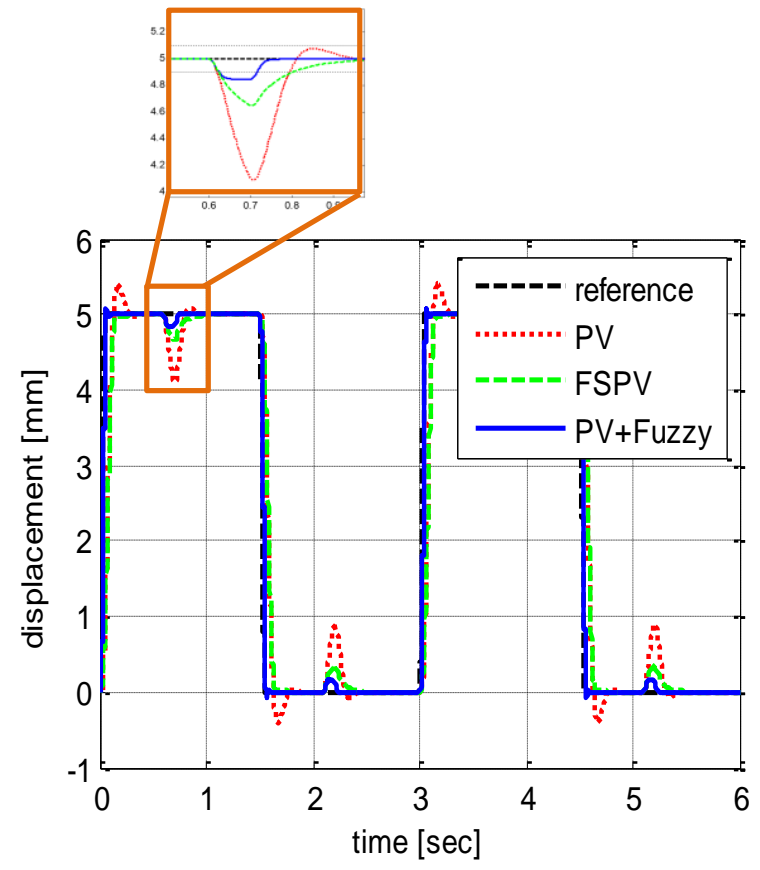

Fig. 8. The DC Servo mechanism performance for (PV, FSPV and prposed controller)

In another way, using Fuzzy logic controller with PV controller as hybrid Controller considered more robust than using PV controller only or using fuzzy gain scheduled PV, where a precise positioning tracking and a critical damping of the load disturbance effect are provided. The control signal components of proposed controller are shown in Fig. 9. The obtained control signal of proposed controller (shown as dash blue line) is illustrated in Fig. 10 in comparing with that obtained using PV controller (shown as solid red line) and FSPV controller (shown as dash green line).
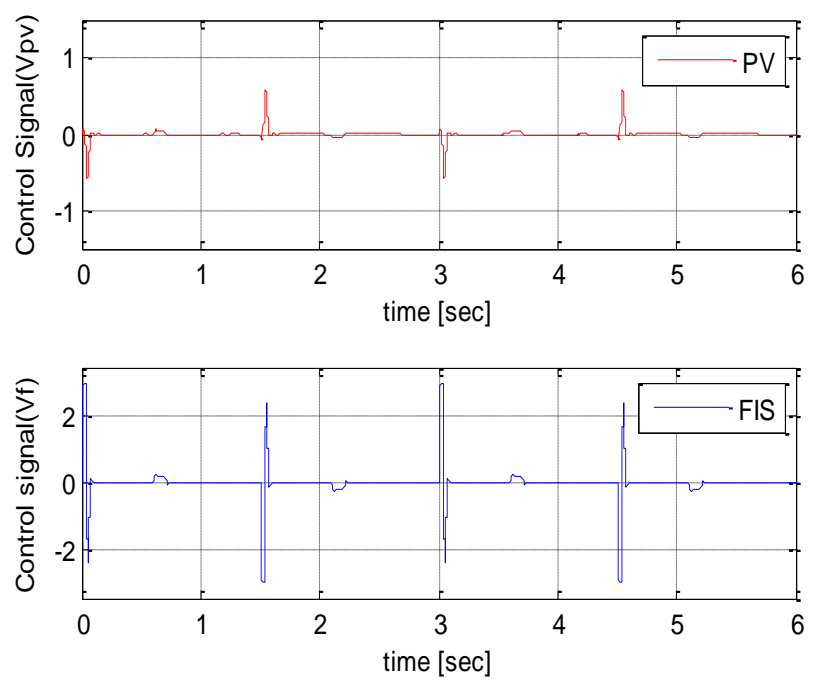

Fig. 9. The control signal components of proposed controller

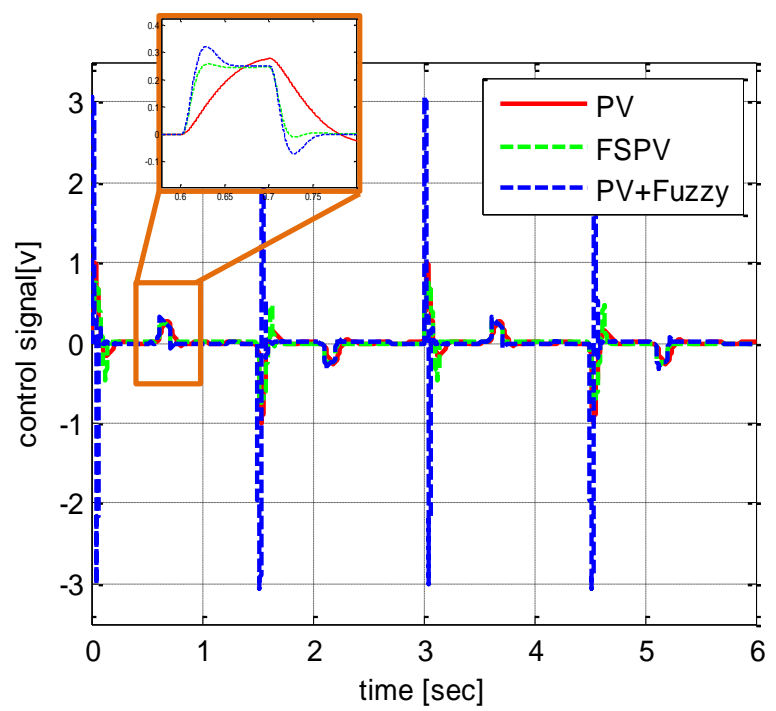

Fig. 10. Control signal for (PV, FSPV and prposed controller)

Finally, the armature current for controllers: PV controller, FSPV controller and Hybrid Fuzzy/PV controller are shown in Fig. 11 as solid red line, dash green line and dash blue line, respectively, as it obvious from the figure $I_{m}$ lies within the saturation limits, i.e. $\mathrm{I}_{\mathrm{m}}$ is limited to a value less than the maximum rated current $\left(\left|\mathrm{I}_{\mathrm{m}}\right| \leq 4.0 \mathrm{~A}\right)$.

The obtained numerical results deduced that the mixing the Fuzzy logic controller with PV controller provide highaccuracy positioning of the cart, i.e. as a result of applying the proposed technique, good transient response and undesirable disturbance effect minimization have been achieved. 
International Journal of Applied Energy Systems, Vol. 2, No. 2, July 2020 ISSN: 2636 - 3712 (Printed Version) ISSN: 2636 - 3720 (Online Version) Special Issue: ICEE-2019

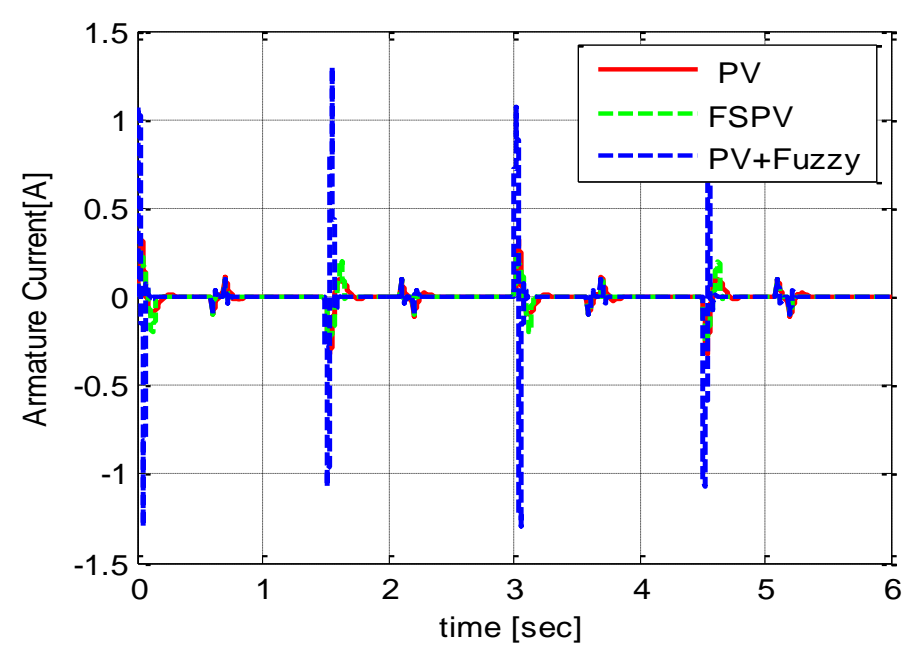

Fig. 11. Armature current

\section{CONCLUSIONS}

Robust controller has been applied in this study for precise positioning of a DC Servo mechanism according to hybrid Fuzzy logic scheme with classical controller i.e. Position-Velocity (PV) controller. The proposed controller has been merged the merit of both Fuzzy and PV controllers. This controller is designed to provide control signal components which based on: $1^{\text {st }}$ fuzzy logic controller with respect to position and velocity error signals, and $2^{\text {nd }} \mathrm{PV}$ controller with respected to position error and velocity signal, in order to provide collected satisfied control signal. The positioning performance using the proposed controller (Hybrid Fuzzy/PV) compared with those of our previous paper 2018 (PV scheduled controller and PV controller) has been provided. The results confirm the effectiveness of the proposed control system as indicated in its ability to track the predetermined positioning path with load disturbances and approach the required specifications.

\section{REFERENCES}

[1] Bindu R., Mini K. Namboothiripad "Tuning of PID Controller for DC Servo Motor using Genetic Algorithm," International Journal of Emerging Technology and Advanced Engineering, vol. 2, no. 3, p. 5, March 2012.

[2] T. H. Mohamed, E. H. Abdelhameed A. M. Hassan, "Real Time Robust Position Contrller for a Cart Moved by a DC Motor through MATLAB," in 16th International Middle East Power Systems Conference (Mepcon'14), Egypt, December 23-24, 2014.

[3] Z. liu and Q. Wang, "Robust Control Of Electrical Machines With Load Uncertainty," Journal of Electrical Engineering, vol. 59, no. 2, pp. 110-112, 2008.

[4] Yahia Makableh, Efficient Control of DC Servomotor Systems Using Backpropagation Neural Networks, Georgia Southern: Spring, 2011.

[5] Abdelgaleel Ahamed Omer AlSheik and Dr. Ebtihal Haider Gismalla Yousif, Speed Control of DC Motor
Using Proportional-Integral-Derivative Controller and Fuzzy Logic, Sudan: Sudan University of Science and Technology, August, 2018.

[6] M. Namazov and O. Basturk, "DC motor position control using fuzzy proportional-derivative controllers with different defuzzification methods," Turkish Journal of Fuzzy Systems (TJFS), vol. 1, no. 1, pp. 3654, 2010.

[7] F. Behrooz, et al. "Review of Control Techniques for HVAC Systems-Nonlinearity Approaches Based on Fuzzy Cognitive Maps," Energies, vol. 11, no. 3, p. 495, 2018.

[8] Shubo Wang, Haisheng Yu, Xuehui Gao and Na Wang, "Adaptive Barrier Control for Nonlinear Servomechanisms with Friction Compensation," Complexity, vol. 2018, no. ID 8925838, p. 11, 2018.

[9] E. H. Abdelhameed and M. Iwasaki, "Precise Positioning Control Using Auto-Tuned Fuzzy Logic Controller," IEEJ, Vols. 130-D, no. 11, pp. 1264-1271, 2010.

[10] X. Xiang, C. Yu, L. Lapierre, J. Zhang and Qin Zhang "Survey on Fuzzy-Logic-Based Guidance and Control of Marine Surface Vehicles and Underwater Vehicles," Taiwan Fuzzy Systems Association and SpringerVerlag GmbH, 2017.

[11] E. H. Abdelhameed, M. M. Hamed, T. H. Mohamed, and G. Elsaady, "Fuzzy-Based Position-Velocity Controller Gain Scheduling for Load Disturbance Rejection in a Positioning Servo System," Twentieth International Middle East Power Systems Conference (MEPCON), p. 6, 2018.

[12] "User Manual, IP02 Base Unit Experiment, Setup and Configuration, (2012 Quanser Inc., Printed in Markham, Ontario, Canada.".

[13] E. H. Abdelhameed, G. Shabib, and S. Abdelraheem, "Optimized P-PI Fuzzy Logic Controller of a Positioning Mechanism with Strain Wave Gearing," 18th International Middle East Power Systems Conference (MEPCON 2016), pp. 40-45, 27-29 December 2016.

[14] Mr.Ch.V.N.Raja and G.U.V.Ravi Kumar, "Comparison between FSC and PID Controller for 5DOF Robot Arm," International Journal of Emerging Trends in Electrical and Electronics, vol. 10, no. 2, 2014. 